\title{
Sector Agroalimentario e INTEgración Regional: UNA Simbiosis NECESARIA PARA LA SEgURIDAD ALIMENTARIA Y NUTRICIONAL
}

\section{AGRI-FOOD SECTOR AND REgIONAL INTEGRATION: a NECESSARY SYMBIOSIS FOR FOOD AND NUTRITION SECURITY}

Oscar E. Fernández-Guillén.

\begin{abstract}
RESUMEN
Mediante una investigación documental-descriptiva y cuantitativa-analítica, apoyada en el cálculo e interpretación de indicadores de posición comercial y dinámica del comercio intrarregional, el trabajo examina la relación existente entre agricultura, integración regional y seguridad alimentaria. Para ello analiza el papel desempeñado por la variable agrícola en el contexto de los acuerdos de integración, caracteriza los elementos que confieren sensibilidad al sector agroalimentario y condicionan su tratamiento especial dentro de las experiencias de regionalismo y evalúa el estado de la integración agroalimentaria regional entre 2001 y 2019 comparando tres esquemas latinoamericanos: ALADI, CAN y MERCOSUR.
\end{abstract}

La discusión central argumenta que la profundización del comercio agroalimentario a través de la integración económica ofrece oportunidades para garantizar la seguridad alimentaria, como instrumento capaz de suministrar alimentos de manera estable y fluida, frente a las turbulencias en los mercados internacionales y con costos transaccionales más bajos.

Se concluye que en América Latina no existe integración desde el punto de vista del intercambio agroalimentario y se ofrece una serie de recomendaciones a nivel de políticas públicas en aras del desarrollo agrícola, del comercio y del fortalecimiento de la integración.

\section{Palabras Clave}

América Latina, integración económica, regionalismo, sector agroalimentario, seguridad alimentaria.

\section{ABSTRACT}

Through a documentary-descriptive and quantitative-analytical research, supported by calculation and interpretation of trade position and intraregional trade dynamics indicators, this work examines relationship between agriculture, regional integration and food security. For this reason, it analyzes the role played by agricultural variable in the context of integration agreements, characterizes elements that confer sensitivity to agri-food sector and conditions its special treatment within regionalism experiences, and evaluates current state of regional agri-food integration between 2001 and 2019 by comparing three Latin American schemes: ALADI, CAN and MERCOSUR.

The central discussion argues that deepening of agri-food trade through economic integration offers opportunities to guarantee food security, as an instrument capable of supplying food in a stable and fluid way (facing turbulences in international markets) and with lower transaction costs. 
Sector Agroalimentario e Integración Regional: una simbiosis necesaria para la Seguridad Alimenticia y Nutricional.

DOI: https://doi.org/10.24215/24689912e027

It is concluded that in Latin America there is no integration from the agri-food trade point of view and offers public policies recommendations for agricultural development, trade and strengthening integration.

\section{KEYWORDS}

Latin America, economic integration, regionalism, agri-food sector, food security. 


\section{INTRODUCCIÓN}

La seguridad alimentaria y nutricional (SAN) se refiere a aquella situación en la cual la población de un determinado territorio tiene garantizado el acceso en todo momento, tanto desde el punto de vista físico como económico, a niveles suficientes de alimentos inocuos y nutritivos que le permitirán disfrutar de una vida activa y sana (NUCEPAL, 2016).

Esta condición de garantía viene dada por la interacción de cuatro componentes que, a su vez, se convierten en las dimensiones básicas de la SAN: 1) la disponibilidad de alimentos en cantidad y calidad suficientes, ya sean de producción nacional o importados; 2) el acceso a alimentos adecuados y nutritivos, debido a que las personas cuentan con recursos físicos y económicos para adquirirlos; 3) la utilización biológica o cubrimiento de las necesidades fisiológicas, por la que se logra un estado de bienestar nutricional y que también involucra el acceso al agua potable, la sanidad y la atención médica; y 4) la estabilidad, elemento transversal a los tres anteriores porque significa que se debe contar con alimentos apropiados en todo momento, sin riesgos de que alguna dimensión pueda verse afectada por situaciones de crisis (NUCEPAL, 2016).

Dentro de este contexto, la integración regional y el comercio agroalimentario derivado de ella constituyen mecanismos que contribuyen con la SAN, en tanto que propician la disponibilidad de alimentos en mayor cantidad y variedad, el acceso a ellos mediante el flujo de mercaderías a menores precios debidos a la disminución de barreras comerciales o de la posible competitividad de los socios integrados, el consumo de los productos y la estabilidad en el suministro por medio de un sólido intercambio intrarregional.

Es por dicha razón que el presente trabajo persigue como objetivo central analizar la estrecha relación existente entre el sector agroalimentario, la integración regional y la seguridad alimentaria, en aras de identificar el rol que la variable agrícola desempeña en los acuerdos comerciales, describir la incidencia del intercambio de mercaderías resultante de la asociación sobre la referida SAN y evaluar la integración agroalimentaria en la región durante los últimos años.

Para tales efectos, consta de cuatro secciones estructuradas de la siguiente forma: la primera abordará la discusión en torno a la complejidad del tema agrícola dentro de los 
procesos de integración; la segunda parte expondrá los nexos entre agricultura, seguridad alimentaria e integración económica como variables interdependientes; la tercera sección versará sobre los retos, las desventajas y las oportunidades que enfrentan el comercio internacional agroalimentario y la integración económica; mientras que el cuarto y último apartado ofrecerá un balance sobre el estado de la integración agroalimentaria en el regionalismo latinoamericano, evaluando y comparando los casos de la ALADI, la CAN y el MERCOSUR para el período 2001 2019. El documento finaliza con una serie de conclusiones en donde también se ofrecen líneas de acción para tratar la problemática abordada a lo largo del mismo.

La investigación realizada es de tipo documental-descriptiva y cuantitativa-analítica, basada en métodos cualitativos, para la obtención, revisión, análisis y procesamiento de documentación bibliográfica, y cuantitativos, para procesar bases de datos, medir y estudiar variables comerciales. Entre los métodos cuantitativos empleados se halla el cálculo e interpretación de indicadores de comercio exterior para comprender la posición comercial y la dinámica del comercio intrarregional en los tres procesos señalados.

\section{COMPLEJIDAD DE LA CUESTIÓN AGRíCOLA: APROXIMACIÓN AL PAPEL DE LA}

\section{AGRICULTURA EN LOS ACUERDOS DE INTEGRACIÓN}

Hablar hoy en día de integración económica o integración regional implica abordar el concepto desde un enfoque multidisciplinario; es referirse a un fenómeno de las relaciones internacionales cuya esencia ya es multidimensional, porque no solo involucra un componente económico, sino que también comprende lo político, lo jurídico y lo sociológico (Olmedo, 2016). En otras palabras, trasciende la teoría clásica iniciada con los aportes de Viner (1950) y nutrida por Balassa (1961), que la circunscribe a aquella política comercial de discriminación puesta en práctica mediante la reducción o eliminación de barreras comerciales solo entre las naciones asociadas (Salvatore, 1987), quienes deciden conformar un nuevo espacio económico a través de la fusión de sus propios territorios aduaneros (Basaldúa, 1999). Esta decisión es voluntaria, entraña un hecho político y una vez formalizada posee un ámbito o alcance (sea temático ${ }^{1} y$ territorial $^{2}$ ) basado en los compromisos asumidos por los Estados

1 Puede abarcar integración política, integración económica y comercial (o comercial con componentes económicos y financieros según el esquema integrador) e integración social; sin 
miembros al momento de adherirse en dicho esquema (Fernández Reyes, 2013) tras la suscripción del acuerdo que da vida al proceso de integración de que se trate.

Las tendencias actuales en el comercio internacional, donde los acuerdos económicos trascienden las fronteras regionales, hacen que se comience a emplear con mayor frecuencia el término Acuerdos Comerciales Preferenciales (ACP) en lugar de integración regional, pues la región ya no es un factor territorial condicionante o aglutinante en la aproximación económica entre países. De manera que la integración comienza a abordarse más ampliamente desde el plano de los ACP, término surgido a partir de estudios publicados por la OMC (2011) -manteniendo la esencia de la teoría clásica y contemplando elementos de "integración profunda"3- que también será empleado en el marco del estudio.

Ahora bien, el sector agroalimentario no escapa del alcance de la integración. Tal y como afirman Mesquita Moreira y Stein (2019),

"La agricultura no acaba en la granja"; es decir, incluye una "compleja red de vínculos hacia atrás y hacia adelante, y vínculos laterales con agentes e instituciones económicos especializados que permiten que los productores compitan en los mercados nacionales o internacionales y respondan a una demanda cambiante" (p. 288).

De esta forma, si bien los vínculos entre sector agrícola e integración inician en el plano comercial por el intercambio de bienes agroalimentarios más allá de las fronteras nacionales, según se profundice el esquema de integración y exista una agenda común de desarrollo para el sector pueden extenderse hasta la coordinación de políticas o la cooperación entre las partes contratantes.

que ello signifique que estas modalidades no puedan conjugarse total o parcialmente en un mismo esquema de integración.

${ }^{2}$ Binacional (entre dos países), regional (entre varios países que se encuentran en una misma región) o multilateral (entre varios países que se encuentran en zonas más amplias que una misma región).

${ }^{3}$ Los ACP van más allá de acordar aranceles y tales elementos de "integración profunda" se clasifican en dos áreas: 1) "OMC+" y 2) "OMC- $X$ ". OMC+ comprende la integración profunda en aquellas áreas abarcadas por la OMC (incluye los aranceles industriales y agrícolas, disposiciones sobre obstáculos técnicos al comercio, servicios, propiedad intelectual y medidas de inversión relacionada con el comercio, leyes ambientales, reglamentaciones sobre el mercado laboral y medidas sobre visados y asilo). Mientras que OMC-X abarca los temas normativos no cubiertos por acuerdos de la OMC (OMC, 2011). 
Dentro de este contexto, al referirse al rol de la agricultura en los ACP, Briceño Ruiz (2001) enfatiza que en la política de integración económica existe originalmente una dicotomía entre comercialismo e intervencionismo y que la variable "agricultura" relativiza tal disyuntiva. Significa, entonces, que la agricultura hace que la política económica manifestada dentro de los ACP responda al contexto de las naciones, a intereses y a estrategias de cada país; es decir, la denominada sensibilidad del sector agrícola dentro de las economías nacionales condiciona el grado de liberalización contemplado en los acuerdos.

Para comprender la sensibilidad del sector agroalimentario basta considerar que éste entraña un amplio sistema cuyo producto satisface requerimientos nacionales $\mathrm{e}$ internacionales y posee encadenamientos aguas arriba (up-stream) y aguas abajo (down-stream). Tal particularidad implica que los sistemas agroalimentarios modernos están conformados por cinco elementos: 1) los bienes agrícolas, obtenidos en las unidades de producción; 2) la cadena de valor de insumos, que enlaza a los productores con sus proveedores de materias primas (empresas agroquímicas, de maquinaria agrícola, de semillas, de biotecnología, etc.) y demás factores productivos (mercados de la tierra y laboral); 3) la cadena de valor del producto, donde convergen procesadores, exportadores, mayoristas y supermercados; 4) servicios laterales, que incluye los servicios financieros, de transporte, logística y tecnologías de la información y la comunicación (TIC); y 5) bienes públicos, como investigación y extensión, servicios sanitarios y fitosanitarios, infraestructura (hard y soft), uso de la tierra y regulación laboral (Mesquita Moreira y Stein, 2019).

En consecuencia, los nexos entre el sector agrícola y el regionalismo pueden tornarse complejos en virtud de todos los elementos que estructuran los sistemas agroalimentarios y de la multiplicidad de intereses que cada uno de sus eslabones podría representar y defender; amén de que en ellos también intervienen tanto el sector público como el privado.

Por otro lado, del tratamiento de la variable agrícola por parte de cada país, en virtud de su importancia sobre la estructura socio-económica, dependerá que exista una tendencia comercialista (liberalizadora) o intervencionista (proteccionista). Así, por ejemplo, la agricultura se ha visto regulada en procesos de integración como el europeo debido a la concepción de su "naturaleza multifuncional", lo que quiere decir que este sector de la economía no solo produce bienes agroalimentarios sino que 
también incide sobre el medio ambiente rural y garantiza una alimentación sana y de calidad para la población (Briceño Ruiz, 2001).

Pastorino (2005) señala que la multifuncionalidad de la agricultura identifica al modelo agrícola europeo y significa que ésta va más allá de la mera producción de bienes, convirtiéndola en prestadora de servicios con funciones sociales y ambientales tales como: mantener la ocupación territorial y coadyuvar con su correcta gestión, conservar el paisaje y el ambiente y promover el bienestar colectivo con el suministro de alimentos de calidad cada vez superior o la generación de empleo. Asimismo, confiere al agricultor la cualidad de ofrecer un servicio público, en tanto gestor del ambiente, que merece ser remunerado e introduce el concepto de externalidades positivas de la agricultura ${ }^{4}$ (servicios positivos en el ambiente, la seguridad alimentaria y el desarrollo rural, entre otros) que, al ser de interés público, deben ser atendidas y pagadas por el mercado o con recursos públicos.

El concepto de multifuncionalidad agraria entraña tres funciones principales para la agricultura europea: 1) función primaria: producir materias primas y alimentos en condiciones competitivas y garantizar la seguridad alimentaria; 2) función ambiental: conservar el medio ambiente y el paisaje rural (como soporte de hábitats y biodiversidad, protección frente a riesgos naturales, soporte $d$ actividades recreativas y marco del turismo rural); y 3) función social: contribuir a la viabilidad de las áreas rurales (generando empleos), al desarrollo territorial equilibrado y a la protección del patrimonio cultural (Atance Muñiz, 2003).

Tales concepciones y amplitud de funciones otorgan especial importancia y prioridad al sector, sustentando la adopción de una política agrícola común (PAC) para unificar criterios y acciones y asignándole un perfil marcadamente proteccionista, característico de la Unión Europea (UE) en cuanto a su tratamiento de la variable agrícola.

Ahora bien, en América Latina se ha considerado durante años que los programas de integración económica deben impulsar el desarrollo agrícola, amén del industrial,

\footnotetext{
${ }^{4}$ La explotación agrícola también produce efectos negativos: malos olores, percolado de agroquímicos y efluentes animales, salinización de las napas, erosión del suelo, pérdida de biodiversidad, contaminación genética, emisión de gases tóxicos o reducción de hábitats para la fauna silvestre. Por ende, "no se puede asignar a la "agricultura", como actividad global, sólo efectos positivos" (Pastorino, 2005, p. 80).
} 
debido a la doble importancia de la agricultura: es un sector económico clave para el PIB de muchos países y representa la fuente de empleo de un amplio porcentaje de la población económicamente activa. No obstante, lo complejo del tema dentro de los ACP latinoamericanos puede resumirse de la siguiente forma:

La complejidad de la cuestión agrícola se origina en los numerosos problemas de orden económico, político, social y técnico que conlleva el sector, y que no pueden ser resueltos sin que previamente cada uno de los países liquide definitivamente las deficiencias estructurales que impiden el armónico crecimiento agrícola interno, y que imposibilitan a la vez el establecimiento y la ejecución de una política de desarrollo agropecuario regional. (Instituto Interamericano de Estudios Jurídicos Internacionales, 1967, p. 193)

Lo anterior revela inconvenientes estructurales propios de cada economía que deben ser abordados en primera instancia para emprender luego una coordinación sectorial a nivel regional. Si existen asimetrías y falta de integración entre los sectores económicos nacionales es prácticamente imposible coordinar una política agrícola común dentro de un esquema de integración.

Por otro lado, los procesos de integración pueden encontrarse con otras dificultades que impiden dicho cometido y deben ser tomadas en cuenta, tales como: 1) homogeneidad en la producción de los países que integran la región (iguales intereses pueden generar conflictos entre los socios); 2) intereses nacionales de autosuficiencia (no se orienta la producción hacia el aprovechamiento de ventajas comparativas); 3) rigidez estructural de la actividad agropecuaria (insuficiencia para abastecer las necesidades comerciales); 4) alta dependencia de los mismos productos de exportación (competencia desventajosa entre países); 5) deficiencias en infraestructura y en tecnificación para el agro comercial (requiere de grandes inversiones para armonizar su crecimiento con el de otros sectores de la economía); 6) baja participación del sector público en la actividad agroalimentaria (escasos recursos presupuestados para el desarrollo agrícola) (Instituto Interamericano de Estudios Jurídicos Internacionales, 1967).

En aras de solventar estas dificultades, es de suma importancia que exista una política agrícola común entre las partes que constituyen un ACP, como por ejemplo un mercado común. Igualmente, el desarrollo agrícola en el ámbito de la integración 
económica requiere de una estructura constituida por tres elementos: 1) planificación uniforme en el sector agroalimentario o planificación del desarrollo agropecuario; 2) integración de la investigación agropecuaria y 3) marco institucional del sector dentro del proceso de integración para que funcione la política agrícola en la región (Instituto Interamericano de Estudios Jurídicos Internacionales, 1967).

Salgado Peñaherrera (1976) sostiene que la integración agroalimentaria ha sido un escollo dentro de los ACP debido a los problemas propios del sector y a su importante peso en las estructuras de las economías nacionales, característico de los países en desarrollo (PED) que dependen en buena medida de él. También asegura que como "las fórmulas de integración se diseñaron para actuar en un contexto económico distinto del que es característico de la agricultura" (p. 8), la incorporación del sector agrícola a la integración puede generar cambios en la estructura económica y en las políticas nacionales, lo que significa que inmediatamente enfrentarían resistencias.

Aunque la agricultura sea considerada como el sector ignorado en la integración latinoamericana porque la industrialización y el aprovechamiento de las mejoras de escala fueron los principales motivos para la unión entre los PED, imperioso es asumir que la agricultura moderna sigue tendiendo hacia la industrialización (Mesquita Moreira y Stein, 2019) y, en consecuencia, puede brindar oportunidades reales para una nueva estrategia de integración basada en las cadenas de valor de la industria agroalimentaria.

Para integrar los sectores agrícolas podría iniciarse con esfuerzos concretos de cooperación, concentrados en desarrollar o aprovechar de manera integral ciertos productos con potencialidades dentro de una misma región, así como mejorar el control sanitario, erradicar enfermedades y solucionar problemas fitosanitarios comunes (Salgado Peñaherrera, 1976); sin omitir la cooperación en materia de investigación, asistencia técnica y transferencia tecnológica, entre otras. De tal forma que la cooperación puede ser la primera y la más segura vía que conduzca hacia la integración sectorial, pero ésta también debe apoyarse sobre la base de una correcta planificación por parte de los gobiernos involucrados a fin de obtener resultados exitosos.

En este sentido, cabe mencionar la Cooperación Internacional para el Desarrollo como otra fuente de recursos que puede contribuir tanto con el desarrollo del sector y sus 
encadenamientos como al fomento de los lazos económicos y la integración entre el país otorgante y sus beneficiarios, pues suele ejecutarse a través de una estrategia tríadica basada en tres ejes: ayudas (donaciones o financiación a bajo costo, y asistencia técnica), comercio e inversión directa. Así, por ejemplo, algunos países de la región han desarrollado sus capacidades productivas en diversas actividades agroalimentarias gracias a la contribución de la Official Development Assistance (ODA) de Japón; entre los que destacan casos de gran impacto como la transformación del Cerrado en Brasil para la explotación de soja, maíz y otros granos, que luego le posicionó como uno de los líderes mundiales en exportaciones de dichos rubros, o el desarrollo de la industria del salmón en Chile, la cual ha crecido hasta llegar a ser uno de los sectores económicos de mayor competitividad externa (Hosono, 2017).

Al final, cooperación e integración agrícola deben visualizarse como medios para mejorar conjuntamente la capacidad productiva interna de la región y su poder de negociación externo en el comercio de productos agroalimentarios.

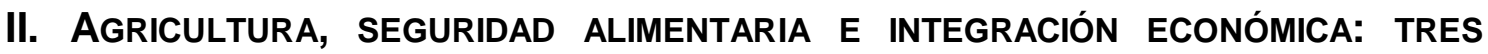 VARIABLES INTERDEPENDIENTES}

La Seguridad Alimentaria y Nutricional (SAN) consiste en "lograr que las personas accedan de manera estable a alimentos sanos y nutritivos" (FAO-ALADI, 2012, p. 8). Debido a su importancia, la SAN apareció con el siglo XXI como tema prioritario en la agenda política internacional contemporánea.

Garantizar la SAN involucra abordar cuatro dimensiones a la vez: 1) la disponibilidad, 2) el acceso, 3) el uso y aprovechamiento y 4) la estabilidad. Al mismo tiempo, atender cada dimensión requiere de un área específica de políticas públicas: 1) área de la oferta de alimentos (políticas e instrumentos de estímulo para asegurar la disponibilidad de alimentos, en cantidad, calidad, oportunidad y sostenibilidad), 2) área de la demanda y acceso a los alimentos por parte de los sectores vulnerables de la población (para garantizar la capacidad de acceso a la alimentación), 3) área de la salud pública y de los consumidores (vinculada con el consumo y acceso a alimentos saludables) y 4) área del financiamiento e inversión pública (para disponer de recursos que permitan llevar a cabo programas productivos y comerciales que aseguren la disponibilidad de alimentos y el acceso a ellos a través de programas de compras 
públicas y de distribución; invertir en equipos y logística de distribución) (FAO-ALADI, 2015).

Figura 01. Dimensiones y áreas de políticas públicas de la SAN.

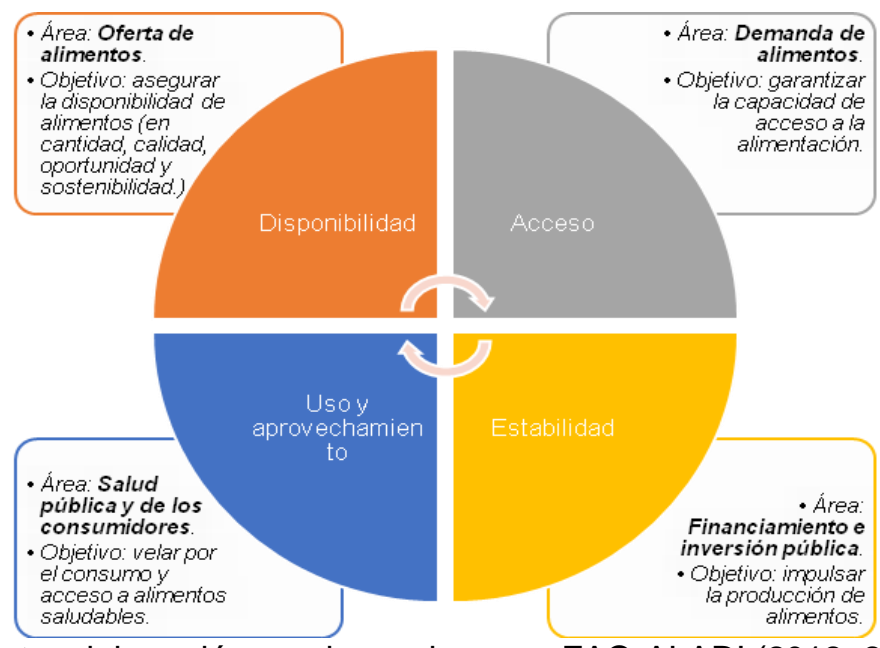

Fuente: elaboración propia con base en FAO-ALADI $(2012 ; 2015)$

Bajo este escenario surge la pregunta ¿qué relación existe entre la agricultura y la integración económica? La respuesta parte por comprender que el sector agroalimentario es "un pilar clave para el desarrollo y el combate al hambre y la pobreza en la región" (FAO-ALADI, 2015, p. 1) y que la integración regional se constituye en un instrumento para garantizar la SAN -no solo a través del intercambio de bienes agrícolas sino también con el fomento de inversiones para fortalecer la producción, desarrollar el sector y facilitar el comercio- y consolidar la posición de un grupo de países o de una región dentro de los sistemas agroalimentarios globales.

Figura 02. Relación entre la agricultura, la integración económica y la SAN.

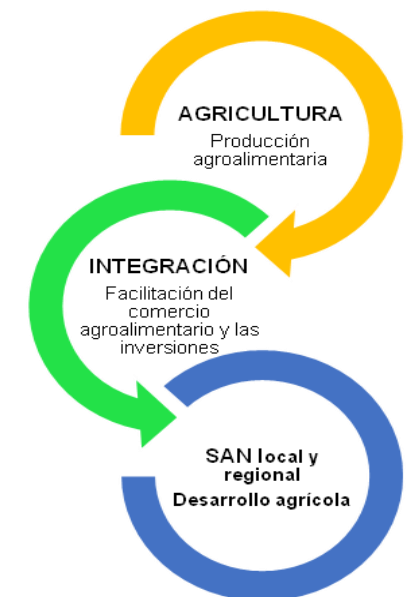

Fuente: elaboración propia. 
América Latina posee enormes potencialidades en recursos naturales -ventajas comparativas- para desarrollar el comercio agroalimentario con base en la enorme variedad de productos cultivados en ella y que son demandados en los mercados mundiales (Yudelman, 1970); a su vez, el intercambio comercial agrícola tiene efectos positivos sobre la SAN, el crecimiento económico y el desarrollo. Su expansión puede conferir estabilidad a la disponibilidad de alimentos y fomentar las inversiones para la creación de cadenas y clúster agroalimentarios de la región (FAO-ALADI, 2015). Es igualmente importante porque contribuye a la generación de divisas, al aumento del ingreso del sector agrícola, al desarrollo del sector agroalimentario, agroindustrial y rural, en general (FAO-ALADI, 2012).

En este orden de ideas, es importante profundizar la integración regional en función de la SAN (FAO-ALADI, 2015), lo cual implica que ésta debe enfocarse simultáneamente hacia dos direcciones: los intereses de los productores locales (sobre todo de la pequeña agricultura) y la necesidad de mejorar el acceso a la alimentación (i.e., los intereses de los consumidores).

Con base en dicho planteamiento y lo analizado hasta ahora, es propicio identificar el principal argumento esgrimido sobre la dificultad que enfrenta el sector agroalimentario dentro de los esquemas de integración: la doble sensibilidad de la cuestión agrícola que traba las negociaciones sobre el sector en los ACP.

Las negociaciones en materia de productos agroalimentarios son altamente sensibles porque en el sector agrícola existe una dualidad de intereses tanto por el lado de la oferta como por el de la demanda; es decir, en ella convergen al mismo tiempo los deseos de los productores y los de los consumidores. Ambos grupos de actores persiguen intereses particulares que pueden ser contrarios y que son atendidos por el sector público. Por ejemplo, una política de precios máximos o de garantía para los productores que no está acompañada por compras públicas o subsidios puede impactar negativamente el consumo de alimentos; igualmente, una política de precios mínimos o de protección para los consumidores sin transferencias públicas para los productores puede desestimular la producción agroalimentaria y derrumbar el ingreso agrícola.

Si bien en la actualidad 33 ACP se encuentran vigentes entre países de la región, muchos de sus miembros poseen economías relativamente cerradas y protegen 
especialmente al sector agrícola, lo que en la práctica y a nivel normativo se evidencia en la enorme lista de bienes agroalimentarios excluidos de los acuerdos de integración, de la misma manera que las mercancías intensivas en mano de obra (IICA, 2019). Esto da luces acerca de la inclinación gubernamental hacia una mayor protección de la producción y de cuán cierta es la apertura comercial.

En definitiva, el sector agroalimentario se caracteriza por poseer una doble sensibilidad (figura 03) que requiere de la intervención del Estado e incide sobre los acuerdos comerciales y su integración sectorial. Por el lado de la demanda se encuentra la protección de los consumidores y, en tal sentido, garantizar la SAN es prioridad. Por el lado de la oferta, los productores (agronegocios y agricultura familiar) claman por protección contra la competencia externa para mantener un satisfactorio nivel de ingresos, unido a la necesidad de los PED de desarrollar el sector y las localidades donde se asientan las unidades productivas.

Figura 03. Doble sensibilidad del sector agroalimentario en los ACP

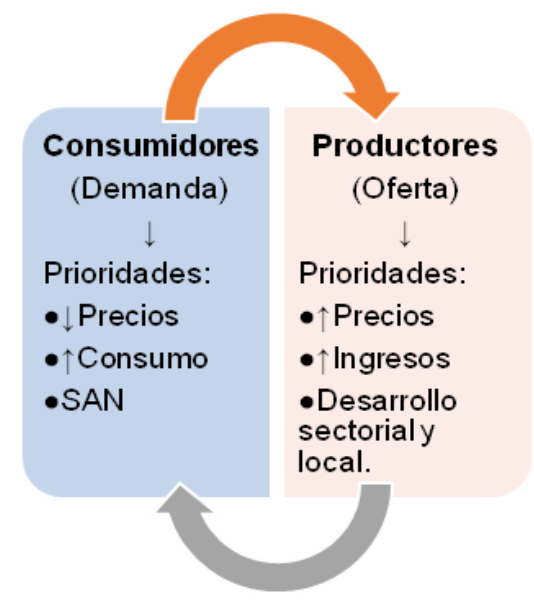

Fuente: elaboración propia.

El reto se encuentra en diseñar e implementar estrategias y políticas que integren las acciones nacionales inherentes a la SAN y el combate al hambre con las negociaciones comerciales y de integración regional, sin desestimar el nexo existente entre los actores referidos, donde la pequeña producción agroalimentaria (agricultura familiar) y el acceso de la población más vulnerable a la alimentación son puntos de honor. Las acciones de política a emprender deben tender a (FAO-ALADI, 2015): 
1) Ordenar el mercado regional concentrando las negociaciones en productos y países específicos con capacidad de complementación de oferta y demanda.

2) Tener en cuenta aspectos que sobrepasan el ámbito arancelario, a fin de resolver los "cuellos de botella" técnicos y económicos de la producción, la comercialización y los servicios a ambos.

3) Facilitar, con un enfoque más allá de las fronteras, la articulación de la pequeña y mediana producción familiar agroalimentaria de los distintos países con los programas nacionales de alimentación para sectores vulnerables.

\section{Comercio INTERnACIONAL AGROALIMENTARIO E INTEGRACIÓN ECONÓMICA: RETOS, DESVENTAJAS Y OPORTUNIDADES}

El comercio mundial agroalimentario ha experimentado un mayor dinamismo desde la década de 1970 por circunstancias como: el desmonte de los sistemas nacionales autárquicos de alimentos claves para la canasta alimentaria básica de la población; la inclusión del comercio agrícola en la Agenda del Libre Comercio del sistema GATTOMC; los impactos del fin de la Guerra Fría en el comercio y la inversión internacional; el regionalismo abierto; el impacto de la revolución científica y tecnológica sobre la producción; la irrupción de economías emergentes en los mercados internacionales ${ }^{5}$, con una expansión en la demanda de alimentos y su efecto sobre el alza de los precios (FAO-ALADI, 2015).

Uno de los desafíos del tema agroalimentario dentro de la integración económica se encuentra en "pasar del reconocimiento político de las estrategias de SAN a la validez de articular las diferentes estrategias, políticas públicas y realidades de mercado a nivel nacional en un Plan Regional de SAN" (FAO-ALADI, 2015, p. 3). Si bien es cierto que en el regionalismo latinoamericano el comercio es un eje fundamental y que el sector agroalimentario en tanto que garante del SAN tiene amplio respaldo político, los avances en materia de integración agrícola han sido lentos y complejos debido a factores como las asimetrías entre Estados, los diversos marcos regulatorios y normas

\footnotetext{
${ }^{5}$ La creciente demanda de productos agroalimentarios por parte de China, por ejemplo, es una oportunidad real para la región que debe ser atendida a través de la integración; entre los productores latinoamericanos, en primer lugar, y entre éstos y el socio asiático, en segundo lugar.
} 
jurídicas y las medidas no arancelarias aplicadas por las naciones (FAO-ALADI, 2015). Toda estrategia integradora en el sector pasa por armonizar dichos obstáculos. Allí se encuentra su razón de ser.

El desarrollo agrícola y la integración económica del sector en América Latina están obstaculizados por problemas estructurales como la resistencia a expandir el comercio agrícola por falta de industrias orientadas a la exportación (aunque haya eficiencia productiva a nivel interno); la protección industrial doméstica y sus efectos sobre los costos de producción agrícola; la "bipolaridad" tecnológica ${ }^{6}$ que caracteriza al sector y lo hace incompatible con una economía nacional integrada; la baja integración entre la estructura del sector agrícola y la estructura de las economías nacionales; y la falta de integración física entre las unidades de producción y los principales centros de actividad económica, como signo de subdesarrollo que dificulta la movilidad de los recursos y el funcionamiento del mercado (Yudelman, 1970).

Para la SAN es crucial el comercio internacional porque la alimentación "siempre tendrá una relación importante con el intercambio a nivel mundial" (FAO-ALADI, 2012, p. 14). No obstante, dicha importancia depende de elementos nacionales como: la composición de la canasta básica de alimentos, las ventajas comparativas que posee un determinado país en la producción de esos rubros, el tamaño del mercado doméstico y la política comercial de la nación (FAO-ALADI, 2012).

Se aboga por la apertura del comercio agroalimentario en términos de sus ventajas, tales como: permite una mayor disponibilidad de alimentos, en cantidad y variedad; facilita un mayor acceso a ellos, a raíz de los menores precios que puede generar la competencia en los mercado; ofrece mayores ingresos a la agricultura, mientras mayor sea el volumen del comercio transado; incentiva un uso más eficiente de los recursos productivos; y es una fuente de ingresos para el país, que puede ser destinado para el consumo o la inversión nacional (FAO-ALADI, 2012).

Las desventajas del comercio internacional sobre la SAN se relacionan con los impactos negativos de la liberalización comercial en la población rural que depende de la agricultura y no es competitiva sin protección estatal, lo que traería como

\footnotetext{
${ }^{6}$ Dualismo productivo-tecnológico, porque abarca tanto a unidades de producción familiares, tradicionales y atrasadas tecnológicamente como a unidades multifamiliares, comerciales y adelantadas en tecnología.
} 
consecuencia el desplazamiento de dichos agricultores del mercado local, la pérdida de sus ingresos y la reducción de su acceso a los alimentos (FAO-ALADI, 2012).

Los efectos del comercio en la SAN dependerán de factores como la capacidad exportadora diversificada de los países y su incidencia sobre la obtención de divisas para importar alimentos, los términos de intercambio entre su canasta de productos de exportación e importación, la política cambiaria y la reserva de divisas (FAO-ALADI, 2012). Asimismo, la relación entre la liberalización comercial y la SAN estará determinada por las políticas agrícolas internas. En consecuencia, la inexistencia de coordinación de políticas agrícolas nacionales es uno de los principales obstáculos que impide la integración en el sector agroalimentario, debido a las divergencias nacionales existentes en este campo. No obstante, tal dificultad puede constituirse en una razón de peso para trabajar en procura de la integración.

Se concluye que la profundización del comercio agroalimentario a través de la integración económica ofrece oportunidades para mejorar la SAN, máxime si se considera la vulnerabilidad de los países importadores netos, las incertidumbres del contexto económico regional y mundial, la volatilidad y la tendencia al alza de los precios de los alimentos. De tal manera que la integración representa el instrumento a través del cual puede garantizarse un suministro de alimentos estable y fluido frente a las turbulencias en los mercados internacionales, con bajos costos transaccionales. Además, cuando se materializa entre países próximos puede estimular el comercio agrícola con menores costos de transporte gracias a su cercanía, para lo cual también coadyuvan los avances en infraestructura física, la reducción de barreras comerciales, la similitud de hábitos y tradiciones alimenticias entre los socios, entre otros (FAOALADI, 2012).

Valga señalar las posibles ventajas que generaría la integración económica sobre el sector agroalimentario: 1) oportunidad de aprovechar las economías de escala cuando las necesidades técnico-económicas requieran mercados de mayores dimensiones para reducir los costos de producción (el desarrollo agrícola y las industrias derivadas se beneficiarían de ello); 2) expansión de la producción agrícola y mayor oferta exportable en determinados productos, mayor comercio intrarregional y extrarregional y, por consiguiente, mejoras en la balanza comercial agroalimentaria; 3) especialización en la producción agroalimentaria, lo que crearía comercio en la medida en que la producción nacional de costos altos sea sustituida por la producción regional 
de costos bajos (más eficiente), amén de que la especialización y el mejor rendimiento de los factores liberaría recursos que pueden destinarse a otros fines productivos; 4) mejoras en la relación real de intercambio, considerando que un grupo de países constituido en bloque puede negociar a nivel internacional con mayor peso que si lo hicieran por separado; 5) nuevos incentivos para los inversionistas, cuyos recursos pueden contribuir a la especialización de la producción agrícola en la región, la autosuficiencia, el comercio exterior y la SAN (Yudelman, 1970).

Por último, se debe tener muy en cuenta que si bien el libre comercio puede contribuir con una mejor distribución de los recursos, tal distribución no generará los niveles de producción que se desean si no existen las inversiones en la cantidad y calidad que son necesarias (Yudelman, 1970). En consecuencia, es tarea de los gobiernos crear y garantizar las condiciones óptimas para propiciar un clima de inversiones idóneo.

\section{Estado DE LA INTEGRACIÓN AGROALIMENTARIA EN EL REGIONALISMO LATINOAMERICANO}

Para cuantificar el éxito de la integración económica suele emplearse como referencia el peso o participación que posee el comercio intrarregional dentro del intercambio total realizado por los países que forman parte del acuerdo en estudio (Bidaurrazaga, 2002; El-Agraa, 1994). Según Hosono (2017), la integración económica se manifiesta en un mayor comercio intrarregional (i.e., un aumento en la participación de las exportaciones intrarregionales [XIR] en las exportaciones totales [XT], así como un aumento en la participación de las importaciones intrarregionales $[\mathrm{MIR}]$ en términos de importaciones totales [MT]) y en una expansión de las inversiones intrarregionales.

Análogamente y en aras de describir la evolución de la integración comercial agroalimentaria en lo que va de siglo $\mathrm{XXI}$, se calcula y analiza el peso del comercio intrarregional agroalimentario (i.e., participación de las exportaciones agroalimentarias intrarregionales [XAAIR] en las exportaciones agroalimentarias totales [XAAT] y participación de las importaciones agroalimentarias intrarregionales [MAAIR] en términos de las importaciones agroalimentarias totales [MAAT]) o índice de comercio intrarregional (Durán Lima y Álvarez, 2011) para el intercambio agroalimentario $\left.(\operatorname{ICIR})_{A A}\right)^{7}$.

${ }_{7{ }^{\prime} C I R_{A A}}=\frac{\sum X X A I R}{\Sigma X A A T}$, para el caso del flujo de exportaciones. Mientras más se aproxime el resultado a 1, será mayor la integración; y mientras más tienda a 0 , menor. 
Valga además definir en qué consiste el intercambio comercial de bienes agroalimentarios y cuáles son las variables o flujos que lo componen. En la práctica, el comercio agroalimentario consiste en el intercambio de los productos correspondientes a las partidas arancelarias que van del capítulo 01 hasta el capítulo 24 del Sistema Armonizado de Designación y Codificación de Mercancías, o Nomenclatura del Sistema Armonizado (SA), definido por la Organización Mundial de Aduanas (FAOALADI, 2015). A su vez, dichos capítulos incluyen productos primarios y procesados. Los primarios se ubican en los primeros capítulos y los procesados se suceden a medida que la codificación avanza de forma ascendente (ver tabla 01).

En consecuencia, el intercambio comercial agroalimentario (ICAA) se refiere a la sumatoria de los flujos comerciales de exportaciones (XAA) e importaciones agroalimentarias (MAA); mientras que el saldo comercial agroalimentario 0 , más comúnmente, balanza comercial agroalimentaria (BCAA) es la diferencia entre las XAA y las MAA.

Tabla 01. Partidas arancelarias del sector agroalimentario.

\begin{tabular}{|c|c|}
\hline Capítulo & Descripción \\
\hline '01 & Animales vivos \\
\hline '02 & Carne y despojos comestibles \\
\hline '03 & Pescados y crustáceos, moluscos y demás invertebrados acuáticos \\
\hline '04 & $\begin{array}{l}\text { Leche y productos lácteos; huevos de ave; miel natural; productos comestibles de origen animal no } \\
\text { expresados ni comprendidos en otra parte }\end{array}$ \\
\hline '05 & Los demás productos de origen animal no expresados ni comprendidos en otra parte \\
\hline '06 & Plantas vivas y productos de la floricultura \\
\hline '07 & Hortalizas, plantas, raíces y tubérculos alimenticios \\
\hline '08 & Frutas y frutos comestibles; cortezas de agrios (cítricos), melones o sandías \\
\hline '09 & Café, té, yerba mate y especias \\
\hline 10 & Cereales \\
\hline '11 & Productos de la molinería; malta; almidón y fécula; inulina; gluten de trigo \\
\hline 12 & Semillas y frutos oleaginosos; semillas y frutos diversos; plantas industriales o medicinales; paja y forraje \\
\hline 13 & Gomas, resinas y demás jugos y extractos vegetales \\
\hline 114 & Materias trenzables y demás productos de origen vegetal, no expresados ni comprendidos en otra parte \\
\hline '15 & $\begin{array}{l}\text { Grasas y aceites animales o vegetales; productos de su desdoblamiento; grasas alimenticias elaboradas; } \\
\text { ceras de origen animal o vegetal }\end{array}$ \\
\hline '16 & Preparaciones de carne, pescado o de crustáceos, moluscos o demás invertebrados acuáticos \\
\hline 17 & Azúcares y artículos de confitería \\
\hline '18 & Cacao y sus preparaciones \\
\hline '19 & Preparaciones a base de cereales, harina, almidón, fécula o leche; productos de pastelería \\
\hline '20 & Preparaciones de hortalizas, de frutas u otros frutos o demás partes de plantas \\
\hline '21 & Preparaciones alimenticias diversas \\
\hline '22 & Bebidas, líquidos alcohólicos y vinagre \\
\hline 23 & Residuos y desperdicios de las industrias alimentarias; alimentos preparados para animales \\
\hline 24 & Tabaco y sucedáneos del tabaco elaborados \\
\hline
\end{tabular}

Fuente: elaboración propia con base en ITC (2020). 
Para analizar el estado de la integración comercial agroalimentaria en América Latina se tomaron como referencia tres esquemas regionales: la Asociación Latinoamericana de Integración (ALADI), el Mercado Común del Sur (MERCOSUR) y la Comunidad Andina de Naciones (CAN), ninguno de ellos con PAC. Asimismo, el comportamiento de dichos ACP será contrastado con el desempeño de la UE en el mismo ámbito, quien sí cuenta con una PAC. El análisis comprenderá el período 2001-2019, con base en los datos suministrados por el TradeMap del International Trade Centre (ITC).

La tabla 02 muestra que entre los años 2001 y 2019 América Latina experimentó una desintegración en el sector agroalimentario, en virtud de que el comercio intrarregional decreció a lo largo del periodo por el lado de las XAA (figura 04). Así, mientras que en 2001 las XAAIR representaron aproximadamente un 16\%, 8\% y $11 \%$ de las XAAT para la ALADI, la CAN y el MERCOSUR, respectivamente, en 2019 explicaron apenas un $11 \%, 5 \%$ y $5 \%$ de las XAAT, aproximadamente. En promedio, entre 2001 y 2019 las XAAIR significaron para la ALADI, la CAN y el MERCOSUR un $13 \%, 8 \%$ y $8 \%$ de las XAAT, respectivamente. Este porcentaje revela que existe una baja integración agroalimentaria por el lado de las exportaciones y refleja que es el resto del mundo el principal destino para sus productos agroalimentarios.

Figura 04. Evolución del peso de las exportaciones agroalimentarias intrarregionales (XAAIR).

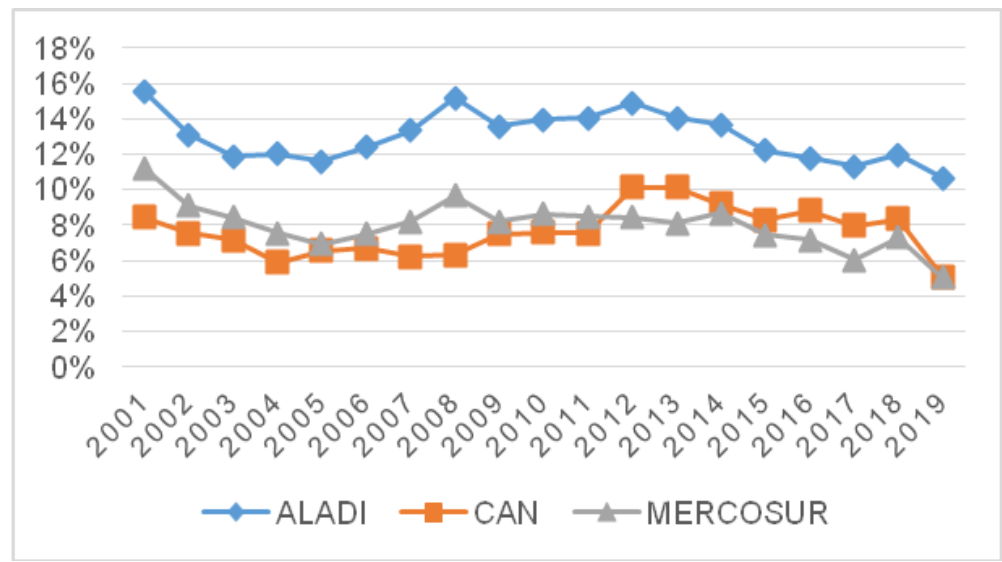

Fuente: elaboración propia con base en tabla 02.

De acuerdo con los datos suministrados por ITC (2020), los principales rubros agroalimentarios exportados intrarregionalmente -según orden de importancia- en 2019 por los tres acuerdos latinoamericanos observados fueron: 
- ALADI: carne; soja; cereales (maíz, arroz y trigo); desperdicios de las industrias alimentarias (alimentos preparados para animales y tortas de soja); pescados, crustáceos y moluscos; plátanos y frutas (capítulos 02 , $12,10,23,03$ y 08 , respectivamente).

- CAN: desperdicios de las industrias alimentarias (preparaciones para alimentar animales, harina de pescado, crustáceos o moluscos); preparaciones de carne, pescado, crustáceos, moluscos o demás invertebrados acuáticos (conservas de pescado); grasas y aceites animales o vegetales (aceite de palma); preparaciones a base de cereales (productos de panadería, pastelería o galletería, pastas alimenticias, y hojuelas de maíz); azúcar; crustáceos (camarones y langostinos), pescados y moluscos(capítulos 23, 16, 15, 19, 17 y 03, respectivamente).

- MERCOSUR: soja; cereales (arroz, maíz y trigo); carne; grasas y aceites animales o vegetales (aceite de soja, margarina y grasa animal); desperdicios de las industrias alimentarias (preparaciones para alimentar animales, tortas de soja); leche y productos lácteos (capítulos 12, 10, 02, 15,23 y 04 , respectivamente).

Un mejor resultado se presentó en el campo de las MAAIR, las cuales constituyeron en promedio, aproximadamente, un $38 \%, 18 \%$ y $47 \%$ de las MAAT para la ALADI, la CAN y el MERCOSUR, respectivamente, entre 2001 y 2019 (tabla 02). El comportamiento de esta variable en los tres ACP osciló entre ligeros ascensos y descensos, pero se mantuvo con cierta tendencia estable alrededor de la media citada, salvo la ALADI que registró un notable ascenso de 2018 a 2019 (figura 05). En este flujo la CAN posee el menor grado de integración, mientras que el MERCOSUR está más integrado por el lado de las MAAIR pues casi un $50 \%$ de sus MAA provienen del mismo bloque.

Figura 05. Evolución del peso de las importaciones agroalimentarias intrarregionales (MAAIR). 


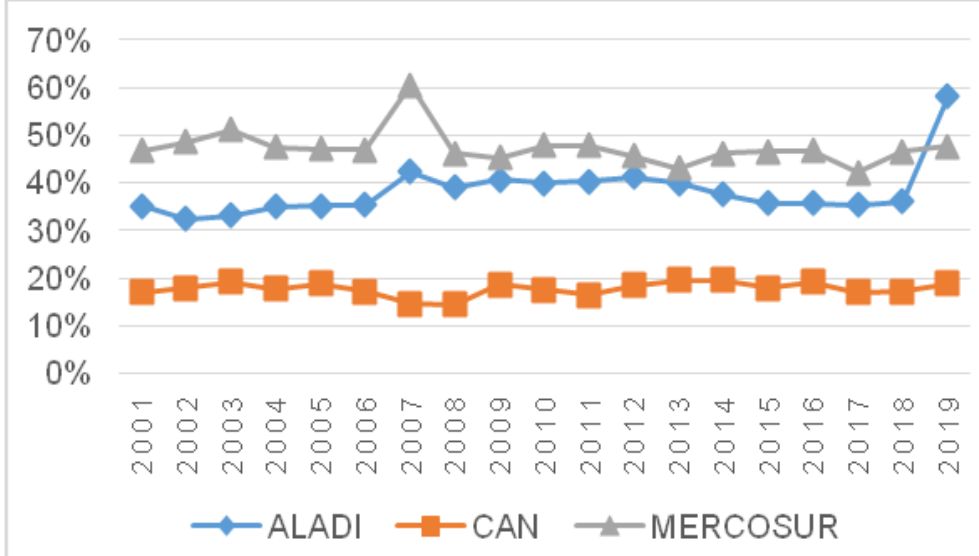

Fuente: elaboración propia con base en tabla 02.

Estas subregiones adquirieron en 2019 -por orden de importancia- los siguientes productos originarios de los mismos acuerdos de integración:

- ALADI: cereales (trigo, maíz y arroz); desperdicios de las industrias alimentarias (tortas de soja y alimentos preparados para animales); carne; grasas y aceites animales o vegetales (aceite de soja, margarina, aceite de girasol); pescados, crustáceos y moluscos; bebidas, líquidos alcohólicos y vinagre (vino y cerveza) (capítulos 10, 23, 02, 15, 03 y 22, respectivamente).

- CAN: desperdicios de las industrias alimentarias (tortas de soja y alimentos preparados para animales); grasas y aceites animales 0 vegetales (aceite de soja, de girasol y de palma); azúcar y artículos de confitería; preparaciones alimenticias diversas, extractos y concentrados de café; preparaciones a base de cereales, harina, almidón, fécula o leche, y productos de pastelería; crustáceos (camarones y langostinos), pescados y moluscos (capítulos 23, 15, 17, 21, 19 у 03, respectivamente).

- MERCOSUR: cereales (trigo, maíz y arroz); productos de la molinería (malta de cebada u otros cereales, harina de trigo); carne; leche y productos lácteos; preparaciones de hortalizas y frutas; bebidas, líquidos alcohólicos y vinagre (vino, cerveza, alcohol etílico y agua)(capítulos 10, $11,02,04,20$ y 22 , respectivamente). 
Con lo anteriormente descrito, se infiere que los niveles de integración agroalimentaria son muy bajos en los tres esquemas de regionalismo latinoamericano, pues ni siquiera la mitad del comercio en el sector se destina hacia o proviene de ellos. El resto del mundo es un mercado más importante para sus productos agroalimentarios, dado que mucho más del $50 \%$ de su valor se transa fuera de cada región.

A diferencia de América Latina, la UE muestra una fuerte integración agroalimentaria. Más del $70 \%$ de sus exportaciones e importaciones de bienes en este sector tienen como destino y origen el mismo bloque (tabla 02 y gráfico 06). En promedio, entre 2001 y 2019 un $75 \%$ de las XAAT de la UE se destinaron a la propia UE, mientras que el $70 \%$ de las MAAT se originaron desde ella. No obstante, la tendencia de las XAAIR ha sido a la baja mientras que la de las MAAIR, al alza (figura 06).

Figura 06. Peso del intercambio agroalimentario intrarregional en la UE (\%).

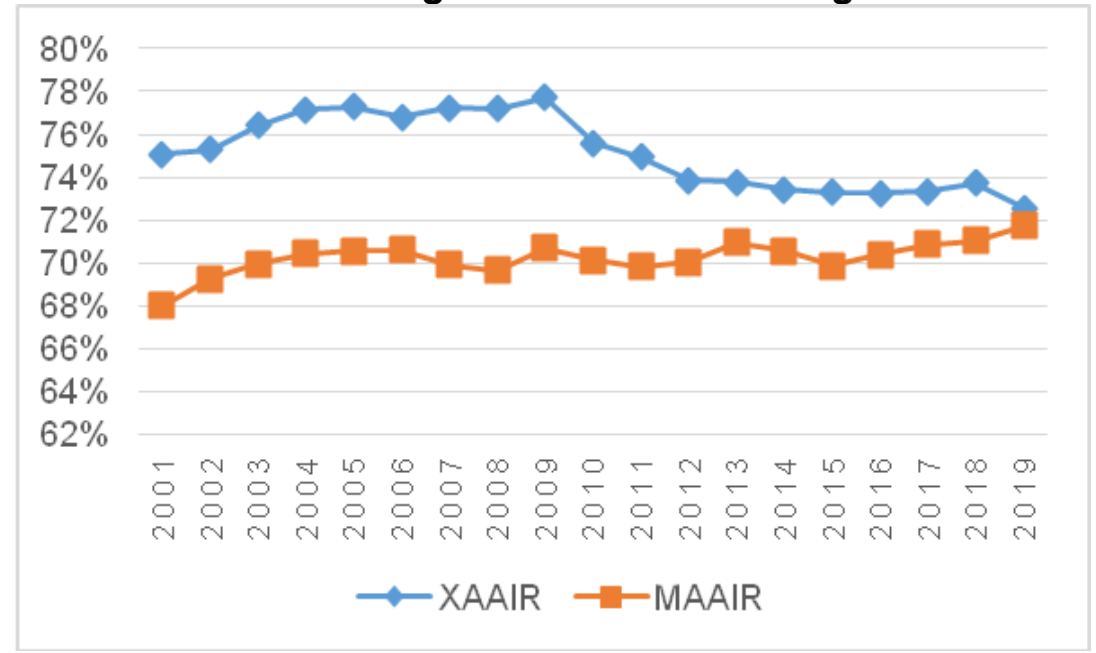

Fuente: elaboración propia con base en tabla 02.

Las principales mercaderías agroalimentarias exportadas intrarregionalmente por la UE en 2019 -en orden de importancia- fueron: carne; leche y productos lácteos; bebidas, líquidos alcohólicos y vinagre (vino, agua, alcohol etílico y cerveza); preparaciones a base de cereales (productos de panadería, pastelería o galletería, pastas alimenticias), frutas; hortalizas, plantas, raíces y tubérculos alimenticios (capítulos 02, 04, 22, 19, 08 y 07, respectivamente). En cuanto a los rubros agroalimentarios europeos importados por el mismo bloque destacaron: leche y productos lácteos; carne; bebidas, líquidos alcohólicos y vinagre (vino, alcohol etílico, agua y cerveza); preparaciones a base de cereales (productos de panadería, 
pastelería o galletería, pastas alimenticias), frutas; hortalizas, plantas, raíces y tubérculos alimenticios (capítulos 04, 02, 22, 19, 08 y 07, respectivamente).

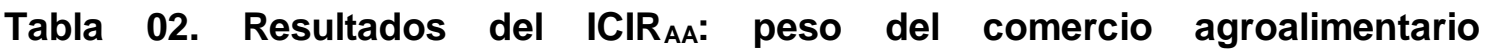
intrarregional dentro del total agroalimentario transado con el mundo (\%)

\begin{tabular}{|c|c|c|c|c|c|c|c|c|}
\hline \multirow{2}{*}{ Año } & \multicolumn{2}{|c|}{ ALADI } & \multicolumn{2}{c|}{ CAN } & \multicolumn{2}{c|}{ MERCOSUR } & \multicolumn{2}{c|}{ UE } \\
\cline { 2 - 8 } & XAAR & MAAR & XAAIR & MAAIR & XAAIR & MAAIR & XAAIR & MAAIR \\
\hline 2001 & $16 \%$ & $35 \%$ & $8 \%$ & $17 \%$ & $11 \%$ & $47 \%$ & $75 \%$ & $68 \%$ \\
\hline 2002 & $13 \%$ & $32 \%$ & $8 \%$ & $18 \%$ & $9 \%$ & $49 \%$ & $75 \%$ & $69 \%$ \\
\hline 2003 & $12 \%$ & $33 \%$ & $7 \%$ & $19 \%$ & $8 \%$ & $51 \%$ & $76 \%$ & $70 \%$ \\
\hline 2004 & $12 \%$ & $35 \%$ & $6 \%$ & $18 \%$ & $8 \%$ & $47 \%$ & $77 \%$ & $70 \%$ \\
\hline 2005 & $12 \%$ & $35 \%$ & $7 \%$ & $19 \%$ & $7 \%$ & $47 \%$ & $77 \%$ & $71 \%$ \\
\hline 2006 & $12 \%$ & $35 \%$ & $7 \%$ & $17 \%$ & $7 \%$ & $47 \%$ & $77 \%$ & $71 \%$ \\
\hline 2007 & $13 \%$ & $42 \%$ & $6 \%$ & $15 \%$ & $8 \%$ & $60 \%$ & $77 \%$ & $70 \%$ \\
\hline 2008 & $15 \%$ & $39 \%$ & $6 \%$ & $15 \%$ & $10 \%$ & $46 \%$ & $77 \%$ & $70 \%$ \\
\hline 2009 & $14 \%$ & $41 \%$ & $8 \%$ & $19 \%$ & $8 \%$ & $45 \%$ & $78 \%$ & $71 \%$ \\
\hline 2010 & $14 \%$ & $40 \%$ & $8 \%$ & $18 \%$ & $9 \%$ & $48 \%$ & $76 \%$ & $70 \%$ \\
\hline 2011 & $14 \%$ & $40 \%$ & $8 \%$ & $16 \%$ & $9 \%$ & $48 \%$ & $75 \%$ & $70 \%$ \\
\hline 2012 & $15 \%$ & $41 \%$ & $10 \%$ & $18 \%$ & $8 \%$ & $46 \%$ & $74 \%$ & $70 \%$ \\
\hline 2013 & $14 \%$ & $40 \%$ & $10 \%$ & $20 \%$ & $8 \%$ & $43 \%$ & $74 \%$ & $71 \%$ \\
\hline 2014 & $14 \%$ & $38 \%$ & $9 \%$ & $20 \%$ & $9 \%$ & $46 \%$ & $73 \%$ & $71 \%$ \\
\hline 2015 & $12 \%$ & $36 \%$ & $8 \%$ & $18 \%$ & $7 \%$ & $47 \%$ & $73 \%$ & $70 \%$ \\
\hline 2016 & $12 \%$ & $36 \%$ & $9 \%$ & $19 \%$ & $7 \%$ & $47 \%$ & $73 \%$ & $70 \%$ \\
\hline 2017 & $11 \%$ & $35 \%$ & $8 \%$ & $17 \%$ & $6 \%$ & $42 \%$ & $73 \%$ & $71 \%$ \\
\hline 2018 & $12 \%$ & $36 \%$ & $8 \%$ & $17 \%$ & $7 \%$ & $47 \%$ & $74 \%$ & $71 \%$ \\
\hline 2019 & $11 \%$ & $58 \%$ & $5 \%$ & $19 \%$ & $5 \%$ & $48 \%$ & $73 \%$ & $72 \%$ \\
\hline \hline Promedio & $\mathbf{1 3} \%$ & $\mathbf{3 8} \%$ & $\mathbf{8} \%$ & $\mathbf{1 8} \%$ & $\mathbf{8} \%$ & $\mathbf{4 7} \%$ & $\mathbf{7 5} \%$ & $\mathbf{7 0} \%$ \\
\hline
\end{tabular}

Fuente: elaboración y cálculos propios con base en ITC (2020).

Al analizar la BCAA desde la óptica total (BCAAT) e intrarregional (BCAAIR) de los cuatro esquemas de integración comparados, se reafirma lo anteriormente expuesto. La figura 07 muestra un saldo superavitario en la BCAAT de la ALADI, la CAN y el MERCOSUR, mientras que registra un saldo deficitario para la UE. Esto ilustra que las subregiones latinoamericanas proveen de productos agroalimentarios al mundo en mayor medida que lo que demanda de él, a diferencia de la UE que los compra en mayor cuantía desde él. En otras palabras, el principal mercado de destino de las XAA latinoamericanas está fuera de la región.

Figura 07. Balanza comercial agroalimentaria total (miles de USD). 


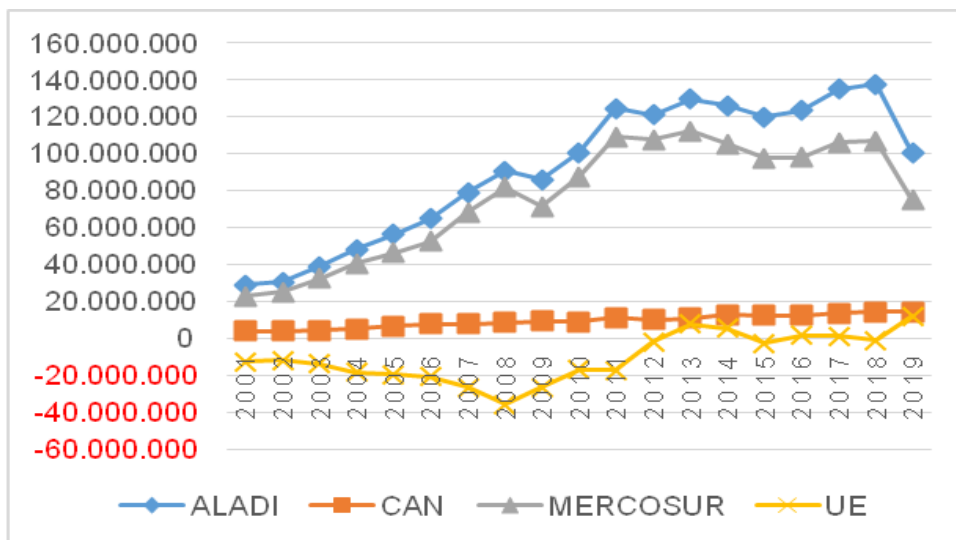

Fuente: elaboración propia con base en ITC (2020).

Por otro lado, al estudiar la BCAAIR (figura 08) se observa una tendencia contraria a la de la BCAAT; es decir, un saldo mayoritariamente negativo para las subregiones latinoamericanas pero positivo para la UE. Significa, entonces, que a lo interno de los tres ACP de América Latina se compran más mercaderías agroalimentarias provenientes de ellos (las MAAIR son mayores que las XAAIR); mientras que a lo interno de la UE el bloque vende más de su propia producción agroalimentaria (las XAAIR son mayores que las MAAIR).

Figura 08. Balanza comercial agroalimentaria intrarregional (miles de USD)

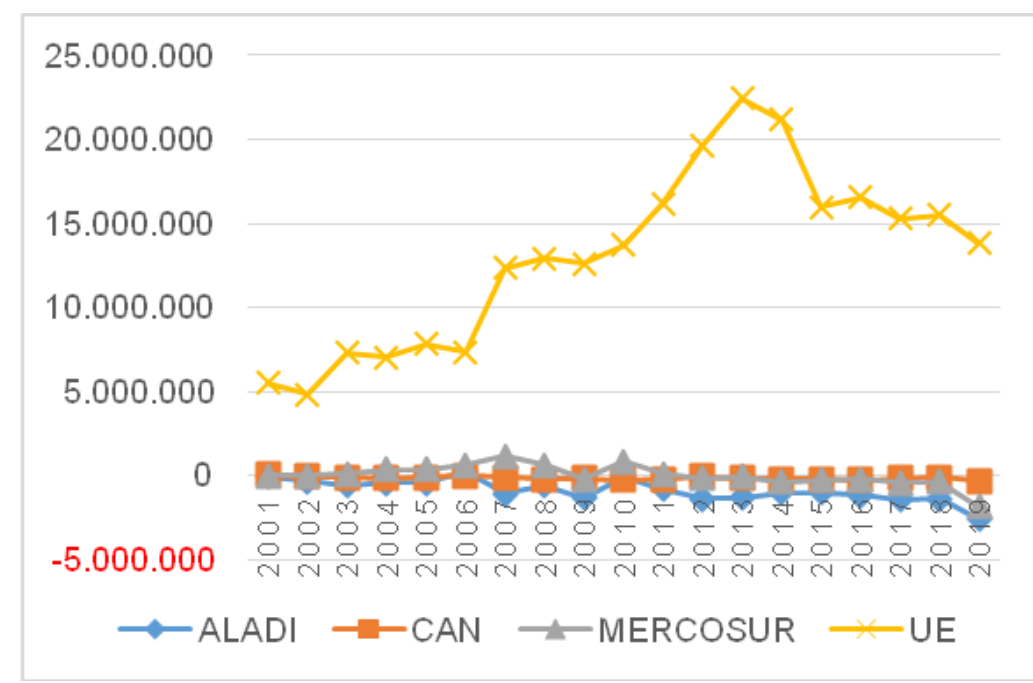

Fuente: elaboración propia con base en ITC (2020).

En definitiva, aunque el ICAA mostró crecimiento durante el período 2001-2019 (ver anexo 01), la integración agrícola en el regionalismo latinoamericano, además de ser baja, tiene mayor significancia a través del flujo de importaciones. Dicho de otro modo, el sector es más importante como origen que como destino para el intercambio comercial intrarregional de sus productos en la ALADI, la CAN y el MERCOSUR. 
Frente a ello, para la UE el sector agroalimentario es más importante como destino para el intercambio de sus bienes intrabloque. Esta tendencia está marcada notablemente por la existencia de una política agrícola común en la UE, al tiempo que en las subregiones latinoamericanas tal fase en la integración de políticas no ha sido alcanzada aún y, por el contrario, sigue habiendo importantes obstáculos artificiales para el comercio en el sector (Durán Lima, 2018).

\section{CONCLUSIONES}

Las condiciones naturales de América Latina y la estructura de las economías nacionales hacen que en la región el sector agrícola siga siendo importante a nivel de su contribución al PIB, de su participación en el comercio internacional, como generador de empleo, como fuente de ingresos y como garante de la SAN. Por ende, y dadas las particularidades de la agricultura moderna, debe entenderse que mejorar la productividad agrícola es clave para el crecimiento económico y la transformación estructural de una región (FAO, 2018; Mesquita Moreira y Stein, 2019). Es aquí donde entra en juego la integración económica a través de medios catalizadores como la cooperación, la inversión y el comercio.

A su vez, el crecimiento de la productividad agrícola depende de mejoras en las capacidades productivas (generalmente respaldadas por instrumentos de política agrícola) y del acceso a los mercados (influidos por el comercio y los instrumentos de política relacionados con el mercado). Por lo tanto, es fundamental garantizar que las políticas agrícolas y comerciales se refuercen mutuamente para el uso eficiente y efectivo de los escasos recursos públicos disponibles en los PED (FAO, 2018, 2019).

Sin embargo, la denominada incoherencia política hace que en los PED la agenda comercial y la agenda de desarrollo agrícola se diseñen por separado, como procesos paralelos en lugar de tratarse como procedimientos complementarios (FAO, 2018, 2019). Esta inconsistencia y falta de visión hacen que el comercio y la agricultura vayan por caminos separados, cuando deberían transitar por uno solo. A fin de minimizar dicha incoherencia es necesario institucionalizar un marco de desarrollo agroalimentario, que priorice la superación de los cuellos de botella y limitaciones relacionadas con la producción, la productividad, el mercado y el comercio. Las dos primeras prioridades requieren de políticas públicas idóneas, tendientes al desarrollo o mejora de dotaciones factoriales claves como infraestructura (soft y hard), capital físico (tecnología) y humano; mientras que las dos últimas entran en el campo de la 
integración regional y los ACP. En este punto, nuevamente queda en evidencia la estrecha relación entre agricultura, comercio e integración como variables de capital importancia para la SAN, el desarrollo del sector agroalimentario, el crecimiento económico y el desarrollo, en general.

El estudio mostró que los niveles de integración agroalimentaria en los tres esquemas analizados dentro del regionalismo latinoamericano (ALADI, CAN y MERCOSUR) son muy bajos y ni siquiera la mitad del comercio agroalimentario se destinó hacia o proviene de ellos en lo que va de siglo XXI. La tendencia a la baja del ICIR AA $_{\text {permite }}$ concluir que, por el contrario, en la actualidad existe desintegración agroalimentaria en los procesos comparados.

Tras el análisis de la dinámica comercial intrarregional quedó en evidencia que el resto del mundo -y no sus socios subregionales- es un mercado más importante para sus productos agroalimentarios, dado que más de la mitad del intercambio sectorial se transa fuera de cada región. Esta evidencia va asociada a la inexistencia de coordinación de políticas sectoriales que fomenten el intercambio intrarregional, en virtud de la presencia de inconvenientes estructurales propios de cada economía, lo que también derivó en la desintegración mostrada a raíz de la baja significancia comercial de los socios.

En tal sentido, es menester atender la realidad ya expuesta con políticas públicas que puedan contribuir a fortalecer la simbiosis entre agricultura, comercio e integración, las cuales deben centrarse en tres áreas fundamentales (FAO, 2018, 2019):

1) Mejorar los sistemas nacionales y regionales para la recopilación, gestión y difusión de datos sobre producción agrícola, precios, existencias, comercialización y comercio. La disponibilidad y el acceso oportuno a datos creíbles y consistentes pueden mejorar la toma de decisiones basada en evidencia por parte de los actores del sector público y privado, y contribuir a una mayor transparencia y previsibilidad en el entorno de políticas para el comercio agrícola.

2) Fortalecer los sistemas agroalimentarios y en especial la cadena de valor down-stream de la granja al mercado (i.e., agregación de valor, distribución, comercialización, etc.). Para ello es necesario identificar primero las cadenas de valor con potencialidades que podrían ser priorizadas por los sectores 
agrícola y comercial, realizar evaluaciones sólidas de su potencial de desarrollo, las intervenciones públicas necesarias y la secuencia de tales reformas para desarrollar cadenas de valor específicas, estrategias, concretas y ancladas en la realidad del entorno. Esto sería de capital importancia para implementar medidas de política que incentiven a los actores privados y requeriría la coordinación de políticas para su implementación y monitoreo, pues no debe quedar solo en la etapa de formulación.

3) Mejorar las capacidades nacionales y las estructuras institucionales de coordinación para la aplicación efectiva de las medidas sanitarias y fitosanitarias (MSF) y las medidas de facilitación del comercio (sobre todo en lo inherente a obstáculos no arancelarios, como administrativos, empaques, etc.), pues solo así se garantizaría que la aplicación de las MSF y otros procedimientos aduaneros y administrativos no constituyan nuevos e innecesarios cuellos de botella para al comercio. Adicionalmente, es vital que se realicen esfuerzos regionales complementarios, como el reconocimiento mutuo o la armonización regional de normas y mecanismos de facilitación del comercio, en aras de reducir verdaderamente los obstáculos al comercio y facilitar el acceso de los pequeños productores a los mercados regionales asociados.

Es importante comprender que la transformación agrícola es necesaria para estimular el desarrollo económico y mejorar la SAN, tanto a nivel nacional como regional. No obstante, los esfuerzos no solo deben centrarse en aumentar la productividad agrícola y desarrollar cadenas de valor agroalimentarias (resolver cuellos de botella locales, en las unidades de producción), también deben enfocarse en solventar los obstáculos descritos para el comercio trasfronterizo. Esto podrá logarse a medida que exista alineación o coherencia entre los planes de desarrollo de la agricultura nacional y las políticas comerciales (FAO, 2018, 2019). De lo contrario, todas las iniciativas integracionistas que pretendan promover la transformación, diversificación y el comercio en el sector agroalimentario se verán limitadas o estancadas en su cometido.

Finalmente, el mundo enfrenta en 2020 los estragos de la pandemia causada por el COVID-19 y América Latina no es ajena a sus impactos sanitarios, económicos ni sociales. Tal y como afirmó la CEPAL (2020), la primera prioridad de la región debe 
ser garantizar el suministro ininterrumpido de productos farmacéuticos, equipos médicos, alimentos y energía, así como proteger los ingresos y el empleo. Es hora de que el regionalismo latinoamericano observe una oportunidad en medio de la tragedia para redefinir sus agendas y que el sector agroalimentario sea, por fin, priorizado en aras de lograr la seguridad alimentaria regional y el bienestar de los más vulnerables.

\section{BiBLIOGRAFÍA}

Atance Muñiz, I. (2003). La provisión de bienes ambientales en el contexto de la multifuncionalidad agraria. En J. C. Tió Saralegui, (coord.), Las subvenciones agrarias europeas a debate (pp. 247-273). Universidad Internacional de Andalucía; AKAL.

Balassa, B. (1961). The theory of economic integration. Richard D. Irwin.

Basaldúa, R. (1999). Mercosur y derecho de la integración. Abeledo-Perrot.

Bidaurrazaga, E. (2002). La integración económica regional como estrategia de desarrollo en el África Austral. Universidad del País Vasco; Servicio Editorial.

Briceño Ruiz, J. (2001). La agricultura y los modelos de integración en la negociación del ALCA. Agroalimentaria, 13(13), 15-28. http://ve.scielo.org/scielo.php?script=sci_arttext\&pid=S1316-03542001000200002

Comisión Económica Para América Latina. (2020). América Latina y el Caribe ante la pandemia del COVID-19: Efectos económicos y sociales. Informe Especial COVID-19, (1), 1-15. https://repositorio.cepal.org/handle/11362/45337

Durán Lima, J. (2018, 7 de noviembre). Los desafíos de la Integración Productiva entre América Latina y Asia Pacífico: ¿Cómo integrarse en cadenas globales de valor y escapar de la dependencia? [ponencia]. Tercer seminario académico del Observatorio América Latina-Asia Pacífico "Hacia una relación integral entre América Latina y Asia Pacífico", Montevideo.

Durán Lima, J. y Álvarez, M. (2011). Manual de comercio exterior y política comercial. Nociones básicas, clasificaciones e indicadores de posición y dinamismo. Naciones Unidas CEPAL; AECID. https://repositorio.cepal.org/handle/11362/3914

El-Agraa, A. M. (1994). Regional integration among developing countries. En E. Grilli, E. Y D. Salvatore, D., (eds.), Handbook of Economic Development (pp. 211-260). Greenwood Press. 
Food and Agriculture Organization (2019). Importance of agriculture and trade policy coherence for agricultural transformation in Africa. Trade Policy Briefs, (34), 1-2. http://www.fao.org/3/ca7288en/ca7288en.pdf

Food and Agriculture Organization y The European Centre for Development Policy Management. (2018). Policy coherence for agricultural transformation in African least developed countries (LDCs). Aligning agriculture and trade policymaking processes. FAO; ECDPM. http://www.fao.org/3/ca0025en/CA0025EN.pdf

Food and Agriculture Organization y Asociación Latinoamericana de Integración (2015). Desarrollo del comercio intrarregional de alimentos y fortalecimiento de la seguridad alimentaria en América Latina $y$ el Caribe. FAO; ALADI. http://www2.aladi.org/nsfaladi/estudios.nsf/FB8C11A8D3C70E4383257E28006C3802/ \$FILE/ALADI-FAO_2015.pdf

Food and Agriculture Organization y Asiciacion Latinoamericana de Integración. (2012). Seguridad alimentaria y comercio intrarregional de alimentos en la ALADI. FAO; ALADI. http://www.fao.org/3/a-as383s.pdf

Fernández Reyes, J. (2013). Curso de Derecho de la Integración (Tom. I). Universidad de Montevideo; Facultad de Derecho.

Hosono, A. (2017). Asia-Pacific and Latin America: dynamics of regional integration and international cooperation. Serie Comercio Internacional, (136), 1-25. https://repositorio.cepal.org/handle/11362/41813

Instituto Interamericano de Estudios Jurídicos Internacionales. (1967). Problemática jurídica e institucional de la integracion de America Latina: ensayo de sistematización. Instituto Interamericano de Estudios Jurídicos Internacionales

Instituto Interamericano de Cooperación para Agricultura. (2019). Programa de Comercio Internacional e Integración Regional. IICA.

Internacional Trade Center. (2020). TradeMap. Consultado el 10 de abril de 2020. https://www.trademap.org

Mesquita Moreira, M. y Stein, E. (eds.) (2019). De promesas a resultados en el comercio internacional: lo que la integración global puede hacer por América Latina y 
el Caribe. Banco Interamericano de Desarrollo (BID). http://dx.doi.org/10.18235/0001886

Naciones Unidas - Comisión Económica Para América Latina. (2016). Seguridad alimentaria, nutrición y erradicación del hambre CELAC 2025: Elementos para el debate y la cooperación regionales. Naciones Unidas CEPAL; FAO; ALADI. https://www.cepal.org/es/publicaciones/40348-seguridad-alimentaria-nutricionerradicacion-hambre-celac-2025-elementos-debate

Olmedo, H. (2016). Midiendo la integración regional del Mercosur en sus 25 años. Ciencia Política, 11(22), 21-43. https://doi.org/10.15446/cp.v11n22.61371

Organización Mundial de Comercio. (2011). Informe sobre el comercio mundial 2011. La OMC y los acuerdos comerciales preferenciales: de la coexistencia a la coherencia. OMC.

https://www.wto.org/spanish/res s/booksp s/anrep s/world trade report11 s.pdf

Pastorino, L. (2005). La política europea de desarrollo rural sostenible. ¿Obstáculo o modelo para el MERCOSUR? Ediciones AI Margen.

Piñeiro, D. (1996). MERCOSUR Y AGRICULTURA: una perspectiva desde los actores. Documento de Trabajo Facultad de Ciencias Sociales Universidad de la República, (17).

Salgado Peñaherrera, G. (1976). Integración y cooperación entre países en desarrollo en el ámbito agrícola. Cuadernos de la CEPAL, (11). https://repositorio.cepal.org/handle/11362/27785

Salvatore, D. (1987). International Economics. Macmillan.

Viner, J. (1950). The customs union issue. Carnegie Endowment for International Peace.

Yudelman, M. (1970). El desarrollo agrícola y la integración económica de la América Latina. Fondo de Cultura Económica. 
Fernández Guillen, OscaR E Economista Cum Laude y Magíster en Economía, mención Políticas Económicas, por la Universidad de Los Andes (ULA, Mérida-Venezuela). Docente e investigador ordinario de la ULA adscrito a la Facultad de Ciencias Económicas y Sociales (FACES), miembro del Centro de Investigaciones Agroalimentarias "Edgar Abreu Olivo" (CIAAL-EAO). Becario del Ministerio de Educación de la República Argentina, perteneciente al Programa de Integración Regional2020, estudiante de la Maestría en Integración Latinoamericana del Instituto de Integración Latinoamericana de la Universidad Nacional de La Plata (UNLP). Líneas de investigación: economía internacional, relaciones económicas internacionales, integración económica, regionalismo, comercio exterior, cooperación internacional y desarrollo. Email: oscarfg.ula@gmail.com / oscared@ula.ve. 
Anexo 01. Valores del comercio agroalimentario total e intrarregión durante el período 2001-2019 (miles de USD).

\begin{tabular}{|c|c|c|c|c|c|c|c|c|c|c|c|c|c|c|c|c|}
\hline \multirow{3}{*}{ Año } & \multicolumn{8}{|c|}{ ALADI } & \multicolumn{8}{|c|}{ CAN } \\
\hline & \multicolumn{4}{|c|}{ Mundo } & \multicolumn{4}{|c|}{ Región } & \multicolumn{4}{|c|}{ Mundo } & \multicolumn{4}{|c|}{ Región } \\
\hline & XАAT & MAAT & BCAAT & ICAAT & XAAIR & MAAIR & BCAAIR & ICAAIR & XAAT & MAAT & BCAAT & ICAAT & XAAIR & MAAIR & BCAAIR & ICAAIR \\
\hline 2001 & 52.192 .711 & 23.268 .432 & 28.924.279 & 75.461 .143 & 8.132 .519 & 8.204 .502 & -71.983 & 16.337 .021 & 7.218 .113 & 3.292 .238 & .925 .875 & 10.510 .351 & 610.772 & 558.185 & 52.587 & 1.168 .957 \\
\hline 2002 & 53.144 .774 & 22.567 .765 & 30.577 .009 & 75.712 .539 & 6.963 .397 & 7.310 .267 & -346.870 & 14.273 .664 & 7.589 .607 & 3.474 .685 & 4.114 .922 & 11.064 .292 & 571.479 & 622.866 & -51.387 & 1.194 .345 \\
\hline 2003 & 63.340 .115 & 24.456 .457 & 38.883 .658 & 87.796 .572 & 7.543 .601 & 8.116 .918 & -573.317 & 15.660 .519 & 8.098 .360 & 3.583 .418 & 4.514 .942 & 11.681 .778 & 580.670 & 691.361 & -110.691 & 1.272 .031 \\
\hline 2004 & 75.927 .385 & 27.419 .695 & 48.507 .690 & \begin{tabular}{|l|}
103.347 .080 \\
\end{tabular} & 9.141 .661 & 9.592 .448 & -450.787 & 18.734 .109 & 9.404 .374 & 4.158 .047 & 5.246 .327 & 13.562 .421 & 555.479 & 738.414 & -182.935 & 1.293 .893 \\
\hline 2005 & 86.249 .777 & 29.669 .086 & 56.580 .691 & 15.918.863 & 10.028 .132 & 10.436 .403 & -408.271 & 20.464 .535 & 11.280 .847 & 4.458 .637 & 6.822 .210 & 15.739 .484 & 738.198 & 842.504 & -104.306 & 1.580 .702 \\
\hline 2006 & 98.400 .718 & 33.692 .116 & 64.708 .602 & 2.092 .834 & 12.210 .635 & 11.935 .801 & 4.834 & 24.1 & 12.948 .167 & 5.15 & 5.424 & 0.910 & 867.116 & 889.180 & -22.064 & 1.756 .296 \\
\hline 2007 & 9.054 .240 & 885 & 355 & 125 & 01 & 623 & 622 & 32. & 14.6 & 6 & 270 & 21 & 70 & 1.009 .295 & -97.317 & \\
\hline 2008 & 150.802 .125 & 59.937 .830 & 90.864 .295 & 10.739 .955 & 22.882 .361 & 23.454 .176 & 815 & 46.3 & 17.980 .472 & 9.439 .428 & 1.044 & .900 & 135.840 & 58 & -232.918 & 2.504 .598 \\
\hline 2009 & 134.156 .598 & 47.863 .849 & 86.292 .749 & 182.020 .447 & 18.213 .284 & 19.509 .284 & -1.296 .000 & 37.722 .568 & 17.206 .106 & 7.834 .346 & 371.760 & 25.040 .452 & 1.293 .311 & 1.461 .833 & -168.522 & 2.755 .144 \\
\hline 2010 & 155.025 .748 & 54.229 .033 & 100.796 .715 & 209.254 .781 & 21.614 .692 & 21.695 .358 & -80.666 & 43.310 .050 & 18.422 .980 & 9.484 .904 & 8.938 .076 & 27.907 .884 & 1.403 .633 & 1.669 .109 & -265.476 & 3.072 .742 \\
\hline 2011 & 194.362 .435 & 69.752 .864 & 124.609 .571 & 264.115 .299 & 27.330 .066 & 28.100 .719 & -770.653 & 55.430 .785 & 23.263 .447 & 11.993 .302 & 11.270 .145 & 35.256 .749 & 1.756 .962 & 1.963 .857 & -206.895 & 3.720 .819 \\
\hline 2012 & 195.118 .496 & 73.991 .935 & 121.126 .561 & 269.110 .431 & 29.088 .782 & 30.469 .340 & -1.380 .558 & 59.558 .122 & 23.267 .780 & 13.139 .991 & 10.127 .789 & 36.407 .771 & 2.356 .330 & 2.418 .492 & -62.162 & 4.774 .822 \\
\hline 2013 & 205.565 .205 & 75.714 .227 & 129.850 .978 & 281.279 .432 & 28.914 .528 & 30.227 .809 & -1.313 .281 & 59.142 .337 & 24.248 .344 & 13.289 .622 & 10.958 .722 & 37.537 .966 & 2.464 .119 & 2.610 .917 & -146.798 & 5.075 .036 \\
\hline 2014 & 202.431.047 & 76.353 .893 & 126.077 .154 & 278.784 .940 & 27.706 .912 & 28.690 .233 & -983.321 & 56.397 .145 & 26.806 .341 & 13.797 .331 & 13.009 .010 & 40.603 .672 & 2.467 .302 & 2.696 .991 & -229.689 & 5.164 .293 \\
\hline 2015 & 186.235 .737 & 66.390 .608 & 119.845 .129 & 252.626 .345 & 22.721 .442 & 23.705 .402 & -983.960 & 46.426 .844 & 25.140 .603 & 12.841 .964 & 12.298 .639 & 37.982 .567 & 2.090 .107 & 2.312 .612 & -222.505 & 4.402 .719 \\
\hline 2016 & 188.916 .607 & 65.539 .401 & 123.377 .206 & 254.456 .008 & 22.268 .297 & 23.453 .808 & -1.185 .511 & 45.722 .105 & 25.548 .149 & 12.986 .065 & 12.562 .084 & 38.534 .214 & 2.250 .402 & 2.498 .923 & -248.521 & 4.749 .325 \\
\hline 2017 & 204.312.301 & 69.401 .385 & 134.910 .916 & 273.713 .686 & 23.142 .339 & 24.559 .530 & -1.417 .191 & 47.701 .869 & 27.763 .610 & 13.990 .933 & 13.772 .677 & 41.754 .543 & 2.216 .494 & 2.387.354 & -170.860 & 4.603 .848 \\
\hline 2018 & 212.061 .133 & 74.344 .847 & 137.716 .286 & 286.405 .980 & 25.410 .454 & 26.808 .411 & -1.397 .957 & 52.218 .865 & 29.389 .432 & 15.053 .482 & 14.335 .950 & 44.442 .914 & 2.454 .964 & 2.577 .591 & -122.627 & 5.032 .555 \\
\hline 2019 & 128.437 .812 & 27.990 .085 & 100.447 .727 & 156.427 .897 & 13.666 .183 & .270 .637 & -2.604 .454 & 29.936 .820 & 22.086 .671 & 7.548 .780 & 14.537 .891 & 29.635 .451 & 1.130 .718 & 64 & -297.346 & 2.558 .782 \\
\hline med & 42.407 .103 & 50.665 .073 & 91.742 .030 & \begin{tabular}{|l|}
193.072 .177 \\
\end{tabular} & 18.573 .173 & 19.447 .035 & -873.862 & 38.020 .208 & 18.542 .224 & 9.073 .079 & 9.469 .145 & 27.615 .304 & 1.466 .099 & 1.618 .227 & -152.128 & 3.084 .325 \\
\hline
\end{tabular}

Fuente: elaboración propia con base en ITC (2020). 
Oscar E. Fernández Guillen

Sector Agroalimentario e Integración Regional: una simbiosis necesaria para la Seguridad

Alimenticia y Nutricional.

DOI: https://doi.org/10.24215/24689912e027

\begin{tabular}{|c|c|c|c|c|c|c|c|c|c|c|c|c|c|c|c|c|}
\hline \multirow{3}{*}{ Año } & \multicolumn{8}{|c|}{ MERCOSUR } & \multicolumn{8}{|c|}{ Unión Europea } \\
\hline & \multicolumn{4}{|c|}{ Mundo } & \multicolumn{4}{|c|}{ Región } & \multicolumn{4}{|c|}{ Mundo } & \multicolumn{4}{|c|}{ Región } \\
\hline & ХАAT & MAAT & BCAAT & ICAAT & XAAIR & MAAIR & BCAAIR & ICAAIR & ХАAT & MAAT & BCAAT & ICAAT & XAAIR & MAAIR & BCAAIR & ICAAIR \\
\hline 2001 & \begin{tabular}{|l|}
30.133 .438 \\
\end{tabular} & 7.224 .291 & \begin{tabular}{|l|}
22.909 .147 \\
\end{tabular} & 37.357 .729 & 3.380 .552 & 3.382 .611 & -2.059 & 6.763 .163 & \begin{tabular}{|l|l|}
196.968 .526 \\
\end{tabular} & \begin{tabular}{|l|}
209.481 .782 \\
\end{tabular} & -12.513 .256 & 406.450 .308 & \begin{tabular}{|l|l|}
147.910 .471 \\
\end{tabular} & 142.420.710 & 5.489 .761 & \begin{tabular}{|l|l|}
290.331 .181 \\
\end{tabular} \\
\hline 2002 & 30.958.405 & 5.779 .666 & \begin{tabular}{|l|l|}
25.178 .739 \\
\end{tabular} & 36.738 .071 & 2.819 .614 & 2.804 .310 & 15.304 & 5.623 .924 & \begin{tabular}{|l|l|}
216.356 .325 \\
\end{tabular} & 228.272.847 & -11.916 .522 & 444.629 .172 & \begin{tabular}{|l|l|}
162.914 .425 \\
\end{tabular} & 158.094.604 & 4.819 .821 & \begin{tabular}{|l|l|}
321.009 .029 \\
\end{tabular} \\
\hline 2003 & \begin{tabular}{|l|l}
38.486 .371 \\
\end{tabular} & 6.120 .592 & 32.365 .779 & 44.606 .963 & 3.242 .859 & 3.132 .133 & 110.726 & 6.374 .992 & \begin{tabular}{|l|l|}
262.093 .575 \\
\end{tabular} & \begin{tabular}{|l|}
275.809 .053 \\
\end{tabular} & -13.7155 .478 & 537.902 .628 & 200.244 .058 & 192.958.581 & 7.285.477 & 393.202 .639 \\
\hline 2004 & 47.411 .742 & 6.784 .468 & 40.627.274 & 54.196 .210 & 3.569.858 & 3.217 .646 & 352.212 & 6.787 .504 & \begin{tabular}{|l|}
299.614 .156 \\
\end{tabular} & 318.174 .948 & -18.560 .792 & 617.789 .104 & 231.178 .000 & 224.162.080 & 7.015.920 & 455.340 .080 \\
\hline 2005 & 53.626 .256 & 7.113 .987 & 46.512 .269 & 60.740 .243 & 3.732 .328 & 3.352 .722 & 379.606 & 7.085 .050 & \begin{tabular}{|l|}
321.811 .074 \\
\end{tabular} & 341.506 .718 & -19.695 .644 & 663.317 .792 & \begin{tabular}{|l|l|}
248.752 .468 \\
\end{tabular} & \begin{tabular}{|l|}
240.923 .877 \\
\end{tabular} & 7.828 .591 & 489.676 .345 \\
\hline 2006 & 60.904 .365 & 8.371 .030 & $\begin{array}{r}52.533 .335 \\
\end{array}$ & 69.275 .395 & 4.558.324 & 3.931 .127 & 627.197 & 8.489 .451 & \begin{tabular}{|l|}
352.483 .006 \\
\end{tabular} & 373.134.558 & -20.651 .552 & 725.617 .564 & 270.770 .744 & 263.407.597 & 7.363.147 & 534.178.341 \\
\hline 2007 & \begin{tabular}{|l|l|}
77.017 .455 \\
\end{tabular} & 8.495 .798 & 68.521 .657 & 85.513 .253 & 6.311 .472 & 5.138 .801 & 1.172 .671 & \begin{tabular}{|l|}
11.450 .273 \\
\end{tabular} & \begin{tabular}{|l|l|}
421.269 .679 \\
\end{tabular} & \begin{tabular}{|l|l|}
447.775 .415 \\
\end{tabular} & -26.505 .736 & 869.045 .094 & \begin{tabular}{|l|l|}
325.441 .874 \\
\end{tabular} & \begin{tabular}{|l|}
313.073 .673 \\
\end{tabular} & 12.368 .201 & \begin{tabular}{|l|l|}
638.515 .547 \\
\end{tabular} \\
\hline 2008 & 101.847 .637 & 19.889 .073 & 81.958 .564 & \begin{tabular}{|l|}
121.736 .710 \\
\end{tabular} & 9.841 .592 & 9.199 .057 & 642.535 & \begin{tabular}{|l|}
19.040 .649 \\
\end{tabular} & 500.913.387 & 536.585 .910 & -35.672 .523 & 1.037 .499 .297 & \begin{tabular}{|l|}
386.736 .314 \\
\end{tabular} & 373.828 .291 & 12.908.023 & 760.564 .605 \\
\hline 2009 & 87.760 .568 & \begin{tabular}{|l|}
16.315 .694 \\
\end{tabular} & 71.444 .874 & 104.076.262 & 7.204 .957 & 7.396 .781 & -191.824 & \begin{tabular}{ll|}
14.601 .738 \\
\end{tabular} & \begin{tabular}{|l|}
444.085 .541 \\
\end{tabular} & \begin{tabular}{|l|}
470.562 .496 \\
\end{tabular} & -26.476 .955 & 914.648 .037 & 345.209 .708 & 332.602 .846 & 12.606 .862 & 677.812 .554 \\
\hline 2010 & 104.679 .820 & \begin{tabular}{|l|}
17.129 .978 \\
\end{tabular} & 87.549 .842 & \begin{tabular}{|l|}
121.809 .798 \\
\end{tabular} & 9.029 .445 & 8.203 .933 & 825.512 & \begin{tabular}{|l|}
17.233 .378 \\
\end{tabular} & \begin{tabular}{|l|}
467.379 .533 \\
\end{tabular} & \begin{tabular}{|l|}
484.096 .430 \\
\end{tabular} & -16.716 .897 & 951.475 .963 & 353.297 .533 & 339.588 .631 & 13.708 .902 & 692.886.164 \\
\hline 2011 & \begin{tabular}{|l|l|}
132.764 .687 \\
\end{tabular} & 23.371.196 & 109.393.491 & \begin{tabular}{|l|l|}
156.135 .883 \\
\end{tabular} & \begin{tabular}{|l|l|}
11.292 .315 \\
\end{tabular} & 11.182.276 & 110.039 & 22.474.591 & \begin{tabular}{|l|}
555.993 .412 \\
\end{tabular} & 573.380.108 & -17.386 .696 & 1.129.373.520 & 416.650.737 & 400.490 .306 & 16.160 .431 & 817.141.043 \\
\hline 2012 & \begin{tabular}{|l|l|}
132.530 .338 \\
\end{tabular} & \begin{tabular}{|l|}
24.813 .105 \\
\end{tabular} & 7.717.233 & \begin{tabular}{|l|l|}
157.343 .443 \\
\end{tabular} & \begin{tabular}{|l|l|}
11.175 .716 \\
\end{tabular} & 11.328 .850 & -153.134 & 22.504 .566 & \begin{tabular}{|l|}
547.616 .411 \\
\end{tabular} & \begin{tabular}{|l|}
549.406 .078 \\
\end{tabular} & -1.789 .667 & \begin{tabular}{|l}
1.097 .022 .489 \\
\end{tabular} & 404.520 .215 & \begin{tabular}{|l|}
384.890 .067 \\
\end{tabular} & 19.630 .148 & \begin{tabular}{|l}
789.410 .282 \\
\end{tabular} \\
\hline 2013 & 138.683 .807 & 26.283.407 & 112.400 .400 & 164.967.214 & \begin{tabular}{|l|}
11.254 .122 \\
\end{tabular} & 11.326 .807 & -72.685 & 22.580 .929 & \begin{tabular}{|l|}
596.458 .526 \\
\end{tabular} & 588.516 .442 & 7.942 .084 & 1.184 .974 .968 & 440.127 .491 & \begin{tabular}{|l|}
417.687 .068 \\
\end{tabular} & 22.440 .423 & 857.814 .559 \\
\hline 2014 & 130.644 .242 & 25.446 .565 & 105.197 .677 & 156.090 .807 & \begin{tabular}{|l|}
11.366 .993 \\
\end{tabular} & 11.735 .992 & -368.999 & 23.102 .985 & \begin{tabular}{|c|}
601.097 .715 \\
\end{tabular} & 595.447 .391 & 5.650 .324 & 1.196 .545 .106 & 441.272.897 & \begin{tabular}{|l|}
420.104 .127 \\
\end{tabular} & 21.168 .770 & \begin{tabular}{|l|l|}
861.377 .024 \\
\end{tabular} \\
\hline 2015 & 116.973 .530 & \begin{tabular}{|l|}
19.299 .046 \\
\end{tabular} & \begin{tabular}{|l|}
97.674 .484 \\
\end{tabular} & 136.272 .576 & 8.704 .813 & 8.995 .143 & -290.330 & \begin{tabular}{ll|}
17.699 .956 \\
\end{tabular} & 521.694 .420 & 524.219 .031 & -2.524 .611 & 1.045 .913 .451 & 382.297 .336 & 366.306 .517 & 15.990 .819 & 7448.603 .853 \\
\hline 2016 & 116.200 .750 & \begin{tabular}{|l|l|}
18.234 .573 \\
\end{tabular} & \begin{tabular}{|l|}
97.966 .177 \\
\end{tabular} & \begin{tabular}{|l|l|}
134.435 .323 \\
\end{tabular} & 8.340 .286 & 8.540 .872 & -200.586 & 16.881.158 & \begin{tabular}{|l|}
537.059 .991 \\
\end{tabular} & 535.472.245 & 1.587 .746 & 1.072.532.236 & \begin{tabular}{|l|l|}
393.370 .163 \\
\end{tabular} & 376.819.359 & 16.550 .804 & \begin{tabular}{|l}
770.189 .522 \\
\end{tabular} \\
\hline 2017 & 125.127 .662 & \begin{tabular}{|l|}
18.846 .889 \\
\end{tabular} & 106.280 .773 & \begin{tabular}{|l|}
143.974 .551 \\
\end{tabular} & 7.544 .502 & 7.958 .996 & -414.494 & 15.503.498 & \begin{tabular}{|l|}
578.165 .182 \\
\end{tabular} & \begin{tabular}{|l|}
576.726 .060 \\
\end{tabular} & 1.439 .122 & 1.154.891.242 & \begin{tabular}{|l|l|}
423.947 .021 \\
\end{tabular} & 408.670 .838 & 15.276 .183 & \begin{tabular}{|l|l}
832.617 .859 \\
\end{tabular} \\
\hline 2018 & 127.667 .505 & \begin{tabular}{|l|}
20.850 .637 \\
\end{tabular} & 106.816 .868 & \begin{tabular}{|l|}
148.518 .142 \\
\end{tabular} & 9.348 .093 & 9.725 .524 & -377.431 & \begin{tabular}{|l|}
19.073 .617 \\
\end{tabular} & \begin{tabular}{|l|}
610.166 .633 \\
\end{tabular} & \begin{tabular}{|l|}
611.322 .467 \\
\end{tabular} & -1.155 .834 & 1.221 .489 .100 & \begin{tabular}{|l|l|}
449.927 .117 \\
\end{tabular} & 434.420 .087 & 15.507 .030 & \begin{tabular}{|l|l|}
884.347 .204 \\
\end{tabular} \\
\hline 2019 & \begin{tabular}{|l|}
88.406 .742 \\
\end{tabular} & 13.306 .690 & \begin{tabular}{|l|}
75.100 .052 \\
\end{tabular} & \begin{tabular}{|l|}
101.713 .432 \\
\end{tabular} & 4.468 .713 & 6.335 .602 & -1.866 .889 & 10.804 .315 & \begin{tabular}{|l|}
618.193 .392 \\
\end{tabular} & \begin{tabular}{|l|}
605.972 .670 \\
\end{tabular} & 12.220 .722 & 1.224.166.062 & 448.626 .106 & 434.792.208 & 13.833 .898 & \begin{tabular}{|l|l|}
883.418 .314 \\
\end{tabular} \\
\hline medio & 91.675 .017 & \begin{tabular}{|l|l|}
15.456 .668 \\
\end{tabular} & \begin{tabular}{|l|l|}
76.218 .349 \\
\end{tabular} & \begin{tabular}{|l|l|}
107.131 .684 \\
\end{tabular} & 7.220 .345 & 7.204 .694 & 15.651 & \begin{tabular}{|l|}
14.425 .039 \\
\end{tabular} & \begin{tabular}{|l|l|}
455.232 .657 \\
\end{tabular} & \begin{tabular}{|l|}
465.571 .718 \\
\end{tabular} & -10.339.061 & 920.804 .375 & \begin{tabular}{|l|l|}
340.694 .457 \\
\end{tabular} & \begin{tabular}{|l|}
327.644 .288 \\
\end{tabular} & 13.050 .169 & \begin{tabular}{|l|l|}
668.338. \\
\end{tabular} \\
\hline
\end{tabular}

Fuente: elaboración propia con base en ITC (2020). 